\title{
UDL in Online College Coursework: Insights of Infusion and Educator Preparedness
}

\author{
LaRon A. Scott, Ed.D. \\ Peter Temple, M.S. \\ David Marshall, M.A. \\ Virginia Commonwealth University
}

\begin{abstract}
Teacher education programs are increasing the use of online courses to train and prepare teachers. The Universal Design for Learning (UDL) framework is one strategy used to effectively train and prepare special education teachers in the online learning environment. The purpose of this study was to examine participants' perception of UDL in online graduate-level courses and their preparation after completing the online courses using UDL. Mean ratings are reported for course alignment with UDL principles as are teacher preparation ratings. Participants reported that they perceived the online courses to be aligned with the UDL principles and that their learning and preparation was positively impacted. The results contribute to the application of these findings to online coursework and teacher preparation. Limitations and implications are discussed.
\end{abstract}

\section{Introduction}

Enrollment in online courses at the postsecondary level has grown at a rapid pace over the past decade (Allen \& Seaman, 2014). In 2002, approximately 1.6 million students, or $9.6 \%$ of all students attending postsecondary institutions in the United States, were enrolled in an online course (Allen \& Seaman, 2003). By 2010, 6.1 million students participated in at least one online course (Allen \& Seaman, 2011). This represents a large increase (281\%), when compared to the overall growth in postsecondary enrollment during the same time period (18.1\%). The National Center for Education Statistics (NCES) recently released data showing that roughly one in every ten students in post-secondary education are 
exclusively enrolled in online programs (NCES, 2014). With this growing population of students, universities are trying to develop online coursework equivalent to their traditional, in-class counterparts. However, there are concerns over whether online learning can truly prepare highly effective and qualified teachers. Those who challenge the efficacy of online teacher preparation perceive online coursework as less rigorous when compared to face-to-face preparation (Columbaro \& Monaghan, 2009); pedagogy associated with online instruction as second-rate (Cox, 2005); and limited face-to-face interaction between instructor and student which leads to poor preparation and low online course completion (Bambara, Harbour, Davies, \& Athey, 2009). However, for teacher preparation programs (both traditional and online) that are not producing enough qualified teachers to keep up with teacher shortagesparticularly in the area of special education (Thornton, Peldier, and Medina, 2007)—online coursework offers the ability to reach and prepare more individuals that are ready and able to educate the next generation of students. This is especially true for bilingual education teachers (Kennedy, 2013), STEM teachers (Hutchison, 2012), and special education teachers (Thornton, Peldier, and Medina, 2007) that often lead the list of critical shortages of teachers across the nation.

These ongoing discussions regarding the quality of online coursework has generated a conversation about the online preparation of teachers. Universal Design for Learning (UDL) has been widely accepted as a framework for meeting the various needs of students in a traditional setting (Smith, Polloway, Patton, \& Dowdy, 2001; Mcguire, Scott, \& Shaw, 2006; Jimenez, Graf, \& Rose, 2007; Meo, 2008; Powell \& Powell, 2010; Gargiulo \& Kilgo, 2013). UDL, which has a specific focus on accessibility of learning, has emerged as a possible way to enhance the quality of coursework and preparation of students enrolled in online programs. UDL as a framework for online coursework and preparation might ensure a quality learning experience for students. It may also help teacher preparation programs seeking to design and deliver quality instructional experiences for students, and help college programs maintain a level of quality that will improve online teacher preparation. After a thorough review of the literature, we infused UDL into our online coursework, and have come to several notable conclusions regarding its use in postsecondary online environments.

\section{Literature Review}

With the increase in online courses, some have questioned the efficacy of online coursework compared to their traditional counterparts in terms of student academic success (Taylor \& Maor, 2000; Herman \& Banister, 2007; Mebane et al, 2008; Clay, 2012). Xu and Jaggars (2011) challenged the notion that online courses have academic success rates equivalent to face-to-face, traditional university formats. Their study found participants enrolled in online English courses were less successful academically than their traditional counterparts with end of semester final grade averages of $74 \%$ and $77 \%$, respectively (Xu \& Jaggars, 2011). However, this study did not address or compare the student participation and academic success in online coursework. More recent research has found a significant relationship exists between student participation in online coursework and the likelihood of attaining passing grades (Tayebinik \& Puteh, 2013). He (2013) found a positive correlation between the number of questions students asked and regular online class attendance and final grades. This ties in with the engagement factor that more teachers are implementing in the classroom-the more engaged students are, the better their overall academic scores (CAST, 2008; He, 2013).

Teaching an online course is different than traditional classroom instruction. Faculty at multiple universities report a higher level of effort required to teach online courses, utilizing different skillsets (Andresen, 2002; Tanner, Noser, \& Taro, 2009; Morra \& Reynolds, 2010). Instructors need to balance the promotion and guiding of amorphous online instruction with designing the structure of discussion well in advance of the start of a course (Lee, 2012). A two-year study of students in over 50 online MBA programs found that the more active and engaging the instructor, the more they were perceived by 
students as being effective (Arbaugh, 2013). Studies suggest high levels of participation, reflection, and frequency of interaction in online discussions and activities are critical to student academic success in online classes (Duncan, Kenworthy, \& McNamara, 2012; Cacciamani et al, 2012, He, 2013).

The field of online education has been changing as rapidly as the technologies that it is built upon. Web 2.0 applications have increased the options that instructors can utilize when teaching students in online, hybrid, and traditional environments. Traditional approaches to college studies might make less sense when addressing the diverse needs and learning skills of the growing post-secondary institution population (Scott, McGuire, \& Shaw, 2003; Edyburn, 2010). NCES reported nearly 11\% of all students enrolled in universities have a disability (Knapp, Kelly-Reid, \& Grinder, 2010). With this growing and diverse population, it is important to design courses with accessibility in mind. This will reduce the need to retrofit necessary accommodations, and increase students' motivation to learn (Poore-Pariseau, 2010; Edyburn, 2010). By utilizing technologies that students are already using today (i.e. blogs, streaming video, social networking), instructors can continue to diversify teaching experiences and increase student accessibility to learning materials (Grabinger, Applin, \& Ponnappa-Brenner, 2008; Embry, Parker, McGuire, \& Scott, 2005). This ties directly into the principles of UDL-by incorporating these newer technologies, instructors are providing multiple means of conveyance, and likewise granting students new and creative ways to participate in their coursework.

\section{Universal Design for Learning}

UDL is an important set of guidelines that allows all students to access learning based on their needs and interests (CAST, 2008). Its main goal is to help educators address the variability in students' capacities to learn, including those with learning disabilities as well as those with academic proficiencies (Mangiatordi \& Serenelli, 2013). UDL is defined as a scientifically valid framework for guiding educational practice that 1 ) provides flexibility in the ways information is presented, in the ways students respond or demonstrate knowledge and skills, and in the ways students are engaged; and 2) reduces barriers in instruction, provides appropriate accommodations, supports, and challenges, and maintains high achievement expectations for all students (NCUDL, 2013).

UDL is based on research in neuroscience, specifically on the three main neural networks that are involved in the variability of an individual's learning process: 1) recognition networks (fact gathering and categorizing what we see, hear, and read); 2) strategic networks (organizing and expressing our ideas); and 3) affective networks (connecting the learning experience to an emotional background, determining engagement and motivation) (Meyer, Rose, \& Gordon, 2014; Rose \& Meyer, 2002; Edyburn, 2009). To address student needs, three principles were created: provide multiple means of representation, provide multiple means of action and expression, and provide multiple means of engagement (Meyer, Rose, \& Gordon, 2014; Rose \& Meyer, 2002; Edyburn, 2009). Table 1 provides a description of the three principles of UDL and the guidelines that accompany each principle.

Educational technology provides teachers with a convenient way to address the three UDL principles (Edyburn, 2010). UDL embraces the diversity in all learners and their needs, leading educators to diverge from the traditional classroom format in higher education and adapt an inclusive curriculum by providing multiple means of representation. UDL is so intrinsically tied to technology that "to suggest the potential of UDL can be achieved without technology is simply another way to maintain the status quo" (Edyburn, 2010, p. 38). With its deep scientific infrastructure and intrinsic link to technology, UDL is a strong tool to develop online coursework for post-secondary students. 
Table 1 UDL Principles Overview

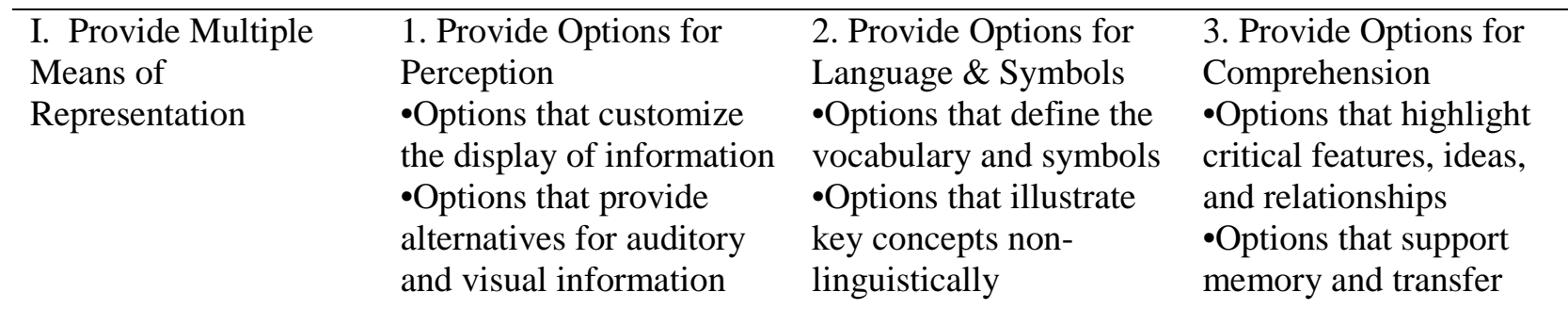

\begin{tabular}{llll}
\hline II. Provide Multiple & 4. Provide Options for & 5. Provide Options for & 6. Provide Options for \\
Means of Action \& & Physical Action & Expressive Skills \& & Executive Functions \\
Expression & $\bullet$ Options for accessing & Fluency & $\bullet$ Options that guide \\
& tools \& assistive & $\bullet$ Options in media for & goal-setting \\
& technologies & communication & $\bullet$ Options that support \\
& $\bullet$ Options in the means of & $\bullet$ Options in tools for & planning \& strategy \\
& navigation & composition \& problem & development \\
& $\bullet$ Options in the mode of & solving & $\bullet$ Options that enhance \\
& physical responses & $\bullet$ Options in the scaffolds capacity for monitoring \\
& & for practice \& & progress \\
& & performance &
\end{tabular}

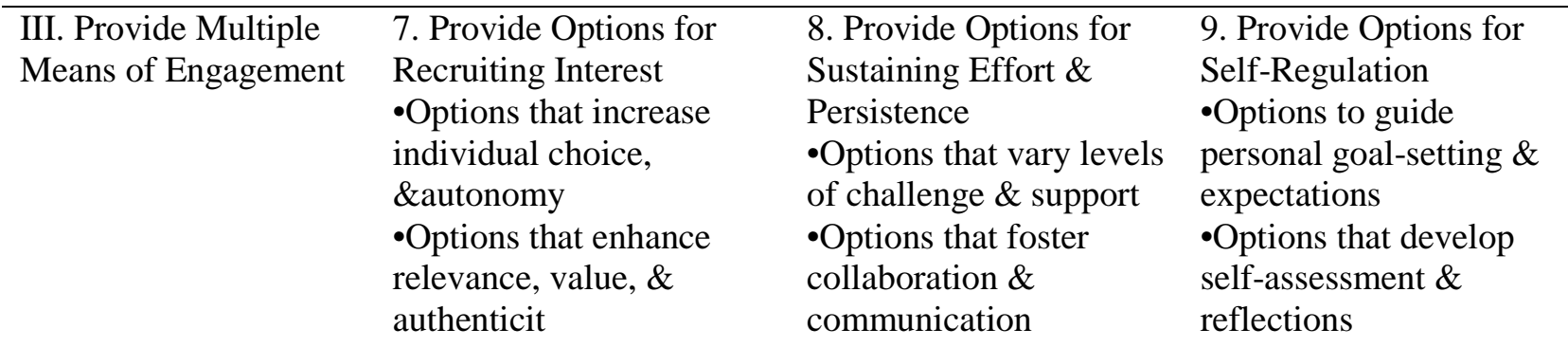

Adapted from Center for Applied Special Technology, 2011.

\section{UDL in College Coursework}

The accessibility of web 2.0 tools and the availability of digital texts has paved the way for a significant increase in UDL implementation within the post-secondary education environment (Gradel \& Edson, 2009). Several studies have discussed how the utilization of the Blackboard online platform "expanded the flexibility of classroom presentations," and allowed professors to "re-evaluate and shift instruction” when needed (Pace \& Schwartz, 2008; Gradel \& Edson, 2009). This does not mean UDL is limited to online instruction. UDL principles can be met in traditional classroom settings by using PowerPoint presentations with printouts of slides, videos with subtitles, or classroom transcripts (Rose, Meyer, \& Hitchcock, 2005). Course websites made available online can enhance the classroom experience by allowing students asynchronous access to materials at any time and anywhere as long as they have an internet connection. While the implementation of UDL does not rely solely on technology, it 
is a useful medium for maximizing student access for instructors designing their courses with web accessibility in mind (Izzo, Murray, \& Novak, 2008).

Despite the fact that UDL can be a strong tool in coursework design, there are few studies which have examined the specific use of UDL principles in post-secondary environments, and fewer studies which have characterized by true experimental designs. Engleman and Schmidt published one of the earliest reports about testing an experimental UDL unit in a graduate-level online teacher education course (2007). One of the goals of the course was to teach graduate students to use UDL with their students, and the course itself was designed using the same UDL principles. After completing the course, students participated in a survey with four questions pertaining to UDL; per each question, students responded positively. Out of 138 participants, 133 felt the choices had distinct differences, 107 preferred having choices every week, 115 reported having more confidence to succeed in the course, and 113 reported that the amount of choices allowed them more opportunities to challenge themselves (Engleman \& Schmidt, 2007). The authors did address two noticeable shortcomings in this design. First, the sample size was too small to generalize beyond the study's population. Also, more specific preference questions should have been asked in the UDL unit (Engleman \& Schmidt, 2007).

Spooner, Baker, Harris, Ahlgrim-Delzell, and Browder (2007) conducted an experiment on the effects of UDL training on lesson plan development in participants from four different on-campus education classrooms, with participants studying in both general and special education fields. Students were randomly assigned to one of either two experimental or two control groups. Each group took a pretest on lesson planning. The experimental groups (one for the general education class, and one for the special education class) had a special one-hour seminar discussing the principles and implementation of UDL in classroom curricula. Results showed that participants in the experimental group improved their lesson plan development significantly after the one-hour intervention compared to the control group. These results suggest that even a simple introduction to UDL can help up-and-coming teachers design lesson plans accessible for all students (Spooner et al, 2007). This study had a few limitations as well. Once again, the low sample size made it difficult to generalize to the entire population. A longitudinal study would be beneficial to determine if teachers continued to use UDL principles when designing their coursework (Spooner et al, 2007). Perhaps the most notable absence, whether by omission or by design, is the fact that there is no mention as to whether or not the college courses themselves were designed with UDL outside of the one-hour seminar. This, too, would affect students' development, and would make for a more compelling argument to use UDL in college coursework in the future.

Morra and Reynolds (2010) wrote an editorial regarding their work on transforming two traditional courses to online classrooms designed utilizing UDL principles. The authors noted that “...specific care was used to take advantage of the online platform in which assignments were delivered" (Morra \& Reynolds, 2010). Assignments were developed with the three principles of UDL in mind; resources were provided with multiple internet-based and highly interactive activities for students to complete the assignment; learners were given choices between multiple ways to complete assessments used towards their final grade, which in turn gave the students motivation to complete their assignments (Morra \& Reynolds, 2010). What Morra and Reynolds provide in their work is a guide on how they planned the courses with each principle in mind; what is not provided is any data regarding how the design affected the academic abilities or content mastery of the students. It would have been beneficial to know how the students felt about the course compared to other courses they have taken (both online and traditional). A post-course survey seeing if the courses really were representative of UDL in their design would also have been useful. Similarly, Rao and Tanners (2011) created an online course designed with UDL and Universal Design for Instruction (UDI) principles in mind in relation to four core areas: course materials, instructional strategies, asynchronous technologies, and synchronous technologies. At the end of the course, all 25 participants completed a questionnaire specifically designed to collect information on their perceptions of the UDL features of the course. Students reported appreciating the choices provided 
by several course elements, including multiple formats for materials; the brief, weekly assignments that were less stressful than high-stakes assessments; and the level of interaction between the instructor and the class, wishing other online course instructors had such dedication (Rao \& Tanners, 2011). This study was short-term (one class in one semester) and looked at a small population of students $(n=25)$. Rao \& Tanner (2011) conceded that this was "the initial phase of research,” (p.226) requiring the collection of data from future UDL-designed courses to build a larger sample size. They also expressed a desire to survey whether or not the course elements are useful to students with disabilities (Rao \& Tanners, 2011).

Smith (2012) tried to develop an instructional checklist, paired with an end-of-semester survey to determine if the principles of UDL were represented in the traditional class itself. The course template was designed to match the course objectives with tasks designed around the recognition, strategic, and affective learning networks, and the follow-up survey determined which of the strategies were used by the students. Responses were favorable towards the implementation of UDL instructional practices, and suggest that when UDL is used to help design courses, the goals are more clearly aligned with the instructional practices (Smith, 2012). It is important to note that at the time of this survey's development, the nine guidelines of UDL curriculum development were not yet published, and a future study examining student perception of the application of these guidelines in a UDL-designed course would be beneficial.

From these previous works, the authors of this study determined a direction for our research. The utilization of UDL in college coursework is still a field of study filled with potential. Colleges are at the beginning stages of developing courses utilizing the UDL principles. With the newer, nine-point guidelines based on these three principles having only recently been developed, courses designed with these in mind need to be evaluated. The authors of this study have developed three online graduate level courses utilizing the nine-point guidelines based the three UDL principles. The purpose of this initial study is to examine whether the online graduate-level course designs are aligned with the UDL principles and whether teachers perceive that the course design improved their preparation.

\section{Methodology}

\section{Purpose of the Study}

The purpose of this initial study was to examine whether three online courses in a graduate-level program are aligned with the UDL principles, and whether teachers enrolled in the online courses perceive that the course design helped to improve their preparation. The authors believe quality online teacher preparation programs can exist, and that the UDL framework can be used to enhance the quality of coursework and preparation of teachers. But can online courses in teacher preparation programs be designed using the UDL guidelines? If so, do teachers believe online courses designed using the UDL principles can help to improve their preparation for the classroom? The authors developed an initial descriptive survey study directed at answering these questions. Descriptive survey studies are used to describe a one-time interaction with groups of people at one point in time, and are often described as the best method for collecting research data prior to performing an experimental study (Jackson, 2009). By obtaining this information, the authors believe that stakeholders can make decisions about online teacher preparation courses and programs in the future.

\section{Procedures}

During the Spring 2014 semester, three online graduate-level courses in the university's special education master's program were designed as online courses using the UDL Guidelines (CAST, 2011). The university is a public university in the Mid-Atlantic region of the United States. Table 2 is an example of how the UDL principles and guidelines (see Table 1) were used to support the development of the online courses. The table also includes examples of assignments and interactions that were developed 
within the online courses. This included full integration of UDL principles, current technology, and development of collaborative teaching skills.

Table 2 Online Course Design with UDL

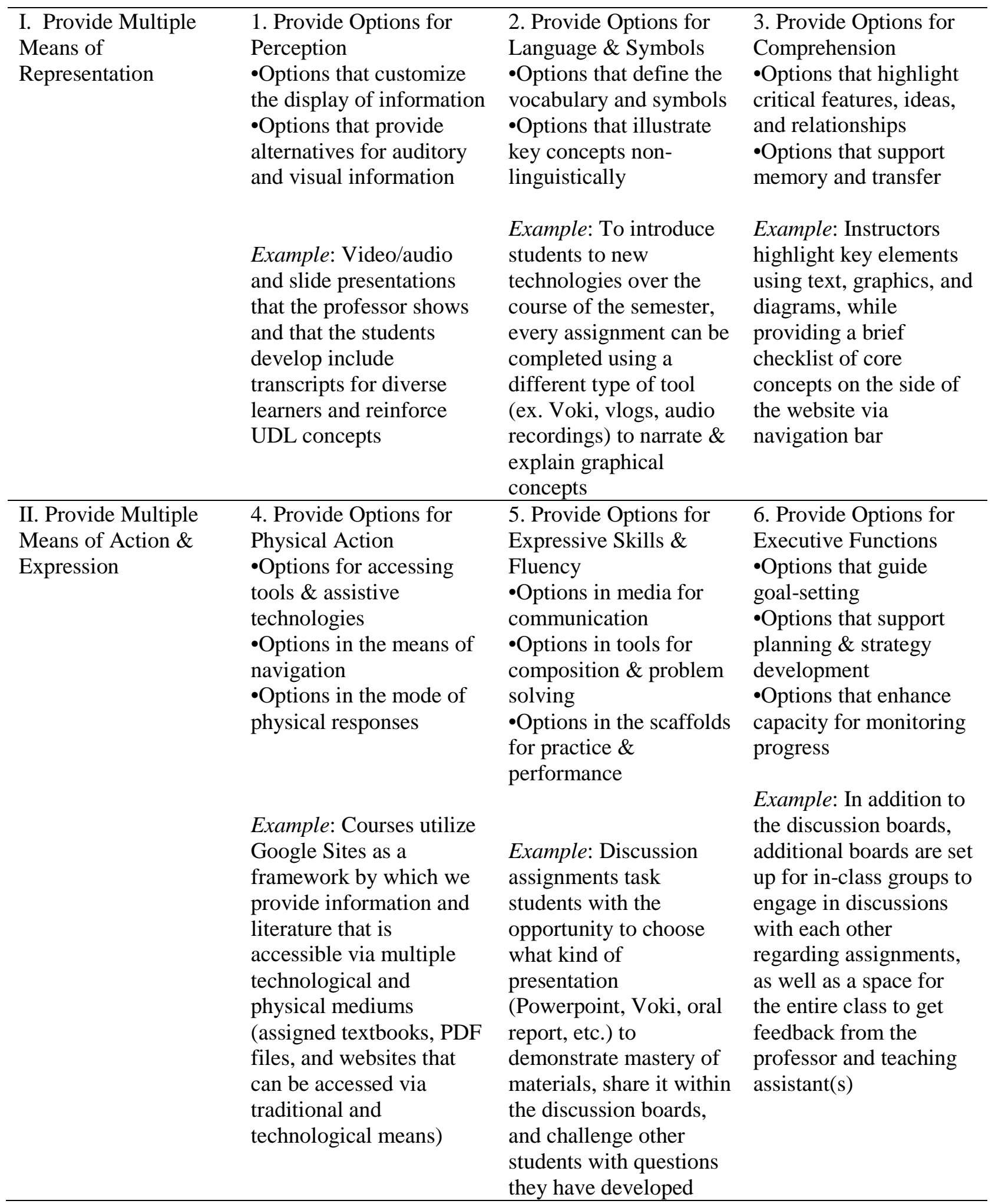




\begin{tabular}{|c|c|c|c|}
\hline & & $\begin{array}{l}\text { based on their } \\
\text { understanding of the } \\
\text { material }\end{array}$ & \\
\hline \multirow[t]{2}{*}{$\begin{array}{l}\text { III. Provide Multiple } \\
\text { Means of Engagement }\end{array}$} & $\begin{array}{l}\text { 7. Provide Options for } \\
\text { Recruiting Interest } \\
\text { •Options that increase } \\
\text { individual choice, } \\
\text { \&autonomy } \\
\text { •Options that enhance } \\
\text { relevance, value, \& } \\
\text { authenticity }\end{array}$ & $\begin{array}{l}\text { 8. Provide Options for } \\
\text { Sustaining Effort \& } \\
\text { Persistence } \\
\text { •Options that vary levels } \\
\text { of challenge \& support } \\
\text { •Options that foster } \\
\text { collaboration \& } \\
\text { communication }\end{array}$ & $\begin{array}{l}\text { 9. Provide Options for } \\
\text { Self-Regulation } \\
\text { •Options to guide } \\
\text { personal goal-setting \& } \\
\text { expectations } \\
\text { •Options that develop } \\
\text { self-assessment \& } \\
\text { reflections }\end{array}$ \\
\hline & $\begin{array}{l}\text { Example: Students will } \\
\text { write a case position } \\
\text { paper regarding a court } \\
\text { case on a topic (ex. LRE, } \\
\text { evaluation, eligibility) } \\
\text { that describes the facts, } \\
\text { issues, and findings of the } \\
\text { order; students } \\
\text { themselves get to choose } \\
\text { both the topic and a case } \\
\text { that interests them }\end{array}$ & $\begin{array}{l}\text { Example: Working } \\
\text { together in groups of 2- } \\
\text { 3, students will develop } \\
\text { a team teaching lesson } \\
\text { plan for a grade 6-12 } \\
\text { class utilizing UDL } \\
\text { techniques. Students } \\
\text { will also collaborate to } \\
\text { create a brief visual } \\
\text { presentation that also } \\
\text { meet UDL standards }\end{array}$ & $\begin{array}{l}\text { Example: Each site has } \\
\text { a section devoted to } \\
\text { grading expectations, } \\
\text { evaluation, \& } \\
\text { assessment, where } \\
\text { students can see the } \\
\text { point values and } \\
\text { determine the } \\
\text { expectations of the } \\
\text { course. Students are also } \\
\text { encouraged to reflect on } \\
\text { the materials via weekly } \\
\text { discussions }\end{array}$ \\
\hline
\end{tabular}

\section{Instrumentation}

During the Spring 2014 semester, three online graduate-level courses in the university's special education master's program were designed using the UDL Guidelines (CAST, 2011). An online survey was developed independently by the authors based on a review of the literature, the UDL Guidelines (CAST, 2011), and the online courses. The survey contained demographics such as age, ethnicity, gender, and reason for enrolling in the online graduate-level course(s). The survey was presented to faculty with expertise in UDL and pre-service and in-service teachers in one of the author's graduate level class for feedback $(N=15)$. The authors made revisions and eliminated any questions where negative feedback was provided. The final survey contained a total of 32 questions. However for the purpose of this study, a total of 20 quantitative Likert-type questions were used to gather details on participants' perceptions on the course's alignment to UDL guidelines (Appendix A). The scales within each rating varied from 1 to 5, with lower scores indicating disagreement with the statement and higher scores indicating agreement. The survey was sent via email during the first week in July 2014 using Research Electronic Data Capture (REDCap), the university's online survey system. The authors also sent a follow-up email after approximately one week, and again one week after the courses ended.

\section{Participants}

At the time of this study there were a total of 55 students enrolled across the three online-graduate level courses. The final sample consisted of 37 participants $(n=20$ pre-service teachers; $n=17$ in-service teachers), representing an estimated $67 \%$ response rate. While this participant rate is relatively smalland this is a limitation of the study-the authors will seek a larger sample once more courses are 
redesigned using the UDL principles and student enrollment increases. The majority of participants reported they were taking the course to satisfy degree requirements $(n=28)$, were female $(n=33)$, were between the ages 20-30 $(n=18)$, and were Caucasian/White $(n=28)$. A vast majority of participants $(n=30)$ indicated they have taken an online course before. Finally, the sample varied greatly in how experienced they were with online courses: very experienced $(n=7)$; somewhat experienced $(n=15)$; casually experienced $(n=5)$; somewhat inexperienced $(n=2)$; and very inexperienced $(n=5)$.

\section{Data Analysis}

The results of the survey were analyzed using Excel. Descriptive statistics were calculated for each item in Excel, and the raw scores of survey respondents are reported.

The survey was scored by averaging the response to each of the individual survey questions. The scales within each ratings varied from 1 to 5 , with lower scores indicating that the participant "disagreed" with the statement and higher scores indicated an "agreement" with the survey statement. Descriptive statistics (i.e., mean, standard deviation) are reported (see Tables 3, 4, and 5) below.

\section{Results}

Table 3 depicts the means and standard deviation results of participants reported perceptions regarding the alignment of the online graduate course to the UDL principle for Multiple Means of Representation (MMR). Participants also reported whether they perceived that their learning and preparation was positively impacted as a result of the course alignment with MMR. Overall, Table 3 shows that the participants reported higher mean scores regularly across this UDL principle.

Table 3 Multiple Means of Representation ( $n=37)$

\begin{tabular}{lll}
\hline Course Template & Mean & $\begin{array}{l}\text { Standard } \\
\text { Deviation }\end{array}$ \\
\hline Content provided in multiple, adjustable formats & 4.78 & .480 \\
Information presented in multiple ways & 4.81 & .397 \\
Assignments provided in multiple formats & 4.72 & .560 \\
Learning/Preparation was positively impacted & 4.62 & .545 \\
\hline
\end{tabular}

Table 4 depicts the means and standard deviation results of participants' reported perceptions regarding the alignment of the online graduate course to the UDL principle for Multiple Means of Expression (MME). Participants also reported whether they perceived that their learning and preparation was positively impacted as a result of the course alignment with MME. Overall, Table 4 shows that the participants reported higher mean scores regularly across this UDL principle.

Table 4 Multiple Means of Expression ( $n=37)$

\begin{tabular}{lll}
\hline Course Template & Mean & $\begin{array}{c}\text { Standard } \\
\text { Deviation }\end{array}$ \\
\hline Multiple ways to complete tasks & 4.59 & .600 \\
Multiple ways to express knowledge & 4.83 & .443 \\
Use of technology to express knowledge & 4.81 & .401 \\
Learning/Preparation was positively impacted & 4.72 & .454 \\
\hline
\end{tabular}

Table 5 depicts the means and standard deviation results of participants reported perceptions regarding the alignment of the online graduate course to the UDL principle for Multiple Means of 
Engagement (MMEg). Participants also reported whether they perceived that their learning and preparation was positively impacted as a result of the course alignment with MMEg. As with the two previous principles, Table 5 shows that the participants reported higher mean scores.

Table 5 Multiple Means of Engagement ( $n=37)$

\begin{tabular}{lll}
\hline Course Template & Mean & $\begin{array}{l}\text { Standard } \\
\text { Deviation }\end{array}$ \\
\hline Material relevant and valuable & & .544 \\
Motivation to learn about subject & 4.64 & .835 \\
Website engaged in learning & 4.03 & .973 \\
Multiple instructional methods for involvement & 4.32 & 0.14 \\
Learning/Preparation was positively impacted & 3.97 & .603 \\
\hline
\end{tabular}

\section{Discussion}

In reporting the results of the previous section, we detailed the UDL principles (i.e., multiple means of representation, expression, and engagement) and investigated whether three online courses were aligned with each UDL principle. The authors also sought to gather teachers' perceptions of their learning and preparation while enrolled in the online courses designed using the UDL principles. In this section we discuss what has been learned about integrating UDL into the online courses. As we indicated in our review, UDL may offer ways to enhance the coursework and preparation of students enrolled in online programs. What materialized from this descriptive study was that teachers' insights into the UDL principles - including the multiple ways in which information and material were presented in the courses - were positively impacted. The findings revealed a consensus across participants with respect to whether the online graduate courses aligned with the UDL principles. Specifically, participants rated highly each of the UDL guidelines embedded in the course, with "multiple instructional methods for involvement" having the "lowest" overall rating at a very respectable $(M=3.97)$. We believe that the findings may suggest that the utilization of the UDL principles in online college coursework is promising, and that participants strongly agree having UDL principles infused into online courses may positively impact their learning and preparation.

\section{Limitations}

This study's generalizability is limited by its nature as it is a study focused on one university's program-e.g., the limited sample size, the typical limitations associated with methodologies relying on surveys to collect information, etc. (Visser, Krosnick, \& Lavrakas, 2000). As mentioned above, the number of completed surveys was limited due to the program's population; therefore future studies on this topic will warrant larger samples and higher response completion rates. As well, this study relies on participants' self-reported data. The current data do not report on the quality of their preparation as teachers. Self-reported data is normally determined by how well participants understand the question and their honest depiction of how well they interpret what they are doing and to what degree it is working (Carducci, 2009). The authors of this study attempted to minimize any limitations with this study by conducting a pilot study of the survey and receiving advice about wording and clarity regarding the survey questions. The authors made revisions and eliminated any questions where negative commentary was provided. Because there has been limited research in the area of UDL in college coursework, we believe that the findings reported are of value to the literature on online coursework and UDL. Last, participants were not asked to justify their response to the questions. It would have been valuable to ask participants to justify their ratings in order to get a better understanding of participants' perceptions regarding what components of the course aligned with each UDL principle and why they believe that learning and preparation was improved. 


\section{Implications for Future Research}

In future research, an attempt should be made to increase the number of courses that embed UDL principles and reach out to other universities and programs that follow a similar approach; this will increase the participant pool and provide an opportunity to collect information and data from a variety of educational stakeholders. While the findings of this study confirm course alignment with UDL principles, as collected by the quantitative data, future studies may seek to gather both qualitative and quantitative data in order to gain a more rich, descriptive understanding of participants' perception of UDL alignment and preparation. Limited empirical research currently exists that has evaluated online course delivery methods (Vernon-Dotson, Floyd, Dukes, \& Darling, 2014), and even less that has examined the use of UDL in college coursework. Experimental designs that focus on this topic may indeed be warranted.

Future qualitative, mixed-method, and or experimental design studies may address some of the following questions: How do educators at the college level benefit from UDL embedded in online coursework? What type(s) of training do faculty and university stakeholders require to align online courses with the UDL principles? How does educator preparation improve as a result of UDL in online coursework (e.g., grades, retention rate, graduation rates) (Roberts, Park, Brown, \& Cook, 2011)? Are students of educators who have taken online coursework utilizing UDL principles better prepared? Does a UDL approach in online coursework for special education teachers improve outcomes for students with disabilities?

UDL offers a relatively large number of guidelines to follow. Besides knowing whether courses suggesting they are utilizing UDL principles are truly aligned, it will be important for future research to investigate what options and resources are being utilized to determine whether the desired results can be accomplished. For example, do all online courses utilizing UDL have to follow the same standardization of technology tools and resources in order to be effective?

\section{Implication for Future Practice}

Despite the limitations of this study, there are certain conclusions that can be drawn from the findings. First, a rationale for the UDL framework in online college courses can be made because of its connection with educational technology (Edyburn, 2010). Second, the ability to embed UDL principles in online coursework is presented. Finally, it is apparent that participants perceive that their overall learning and preparation was improved as a result of being enrolled in the course(s) featuring UDL. Despite the fact that there might exist a discrepancy between perception and performance related to learning and preparation, particularly because there was no opportunity in the survey for an examination of participants actual learning and preparation, it may be that participants rated this category as high because they already do well with these skills. In this case, there would be no need to change current practice although research suggests that even a simple introduction to UDL can help up-and-coming teachers design lesson plans accessible for all students (Spooner et al, 2007).

The list of UDL guidelines and examples presented in this study are not extensive (see Table 1). They can be used by faculty at post-secondary education institutions as a starting point for assessing and aligning online college courses to UDL practices. While the UDL principles identified in this study were validated by participants as being aligned with the online courses, the options and examples of how they were presented in the courses can be taught and practiced in multiple ways that can help to enhance how UDL is embedded in online courses. Overall, we are encouraged by the participants' recognition of the UDL principles alignment and their perceived positive preparation as a result of being enrolled in the course(s). We believe that a failure to collect this data may threaten the quality learning experience that is the goal of our work in the online learning community. 


\section{References}

Allen, I. E., \& Seaman, J. (2003). Sizing the opportunity: the quality and extent of online education in the United States, 2002 and 2003. Needham, MA: The Sloan Consortium.

Allen, I. E., \& Seaman, J. (2011). Going the distance: online education in the United States, 2011. Babson Park, MA: Babson Survey Research Group.

Allen, I. E., \& Seaman, J. (2014). Grade change: tracking online education in the United States, 2013. Babson Park, MA: Babson Survey Research Group and Quahog Research Group.

Andresen, B. B. (2002). Design of teacher e-learning. In D. Passey \& M. Kendall (Eds.), TelE-Learning: the challenge for the third millennium (pp. 3-10) New York: Springer Science+Business Media.

Arbaugh, J. B. (2013). Does academic discipline moderate CoI-course outcomes relationships in online MBA courses? The Internet and Higher Education, 17, 16-28.

Bambara, C. S., Harbour, C. P., Davies, T. G., \& Athey, S. (2009). Delicate engagement: the lived experience of community college students enrolled in high-risk online courses. Community College Review, 36(3), 219-238.

Cacciamani, S., Cesareni, D., Martini, F., Ferrini, T., \& Fujita, N. (2012). Influence of participation, facilitator styles, and metacognitive reflection on knowledge building in online university courses. Computers \& Education, 58(3), 874-884.

Carducci, B. J. (2009). The psychology of personality: viewpoints, research, and applications. Malden, MA: Wiley-Blackwell.

CAST, (2008). Universal Design for Learning guidelines version 1.0. Wakefield, MA: Author

CAST (2011). Universal Design for Learning guidelines version 2.0. Wakefield, MA: Author.

Clay, C. (2012).Great webinars: create interactive learning that is captivating, informative, and fun. San Francisco: John Wiley \& Sons.

Columbaro, C. H., \& Monaghan, N. L. (2009). Employer perceptions of online degrees: a literature review. Online Journal of Distance Learning Administration, 12(1). Retrieved from http://www.westga.edu/ distance/ojdla/spring121/columbaro121.html

Cox, R. (2005). Online education as institutional myth: rituals and realities at community colleges. The Teachers College Record, 107(8), 1754-1787.

Duncan, K., Kenworthy, A., \& McNamara, R. (2012). The effect of synchronous and participation on students' performance in online accounting courses. Accounting Education, 21(4), 431-449.

Edyburn, D. (2009). RTI and UDL interventions. Journal of Special Education Technology, 24(2), 46-47.

Edyburn, D. L. (2010). Would you recognize universal design for learning if you saw it? Ten propositions for new directions for the second decade of UDL. Learning Disability Quarterly, 33(1), 33-41.

Embry, P. B., Parker, D. R., McGuire, J. M., \& Scott, S. S. (2005). Postsecondary disability service providers' perceptions about implementing Universal Design for Instruction (UDI). Journal of Postsecondary Education and Disability, 18(1), 34-48. 
Engleman, M., \& Schmidt, M. (2007). Testing an experimental universally designed learning unit in a graduate level online teacher education course. Journal of Online Learning and Teaching, 3(2), 112-132.

Gargiulo, R., \& Kilgo, J. (2013). An introduction to young children with special needs: birth through age eight. Belmont, CA: Cengage Learning.

Grabinger, R. S., Aplin, C., \& Ponnappa-Brenner, G. (2008). Supporting learners with cognitive impairments in online environments. TechTrends, 52(1), 63-69.

Gradel, K., \& Edson, A. J. (2009). Putting universal design for learning on the higher ed agenda. Journal of Educational Technology Systems, 38(2), 111-121.

He, W. (2013). Examining students' online interaction in a live video streaming environment using data mining and text mining. Computers in Human Behavior, 29(1), 90-102.

Herman, T., \& Banister, S. (2007). Face-to-face versus online coursework: a comparison of learning outcomes and costs. Contemporary Issues in Technology and Teacher Education, 7(4), 318-326.

Hutchison, L. F. (2012). Addressing the STEM teacher shortage in American schools: ways to recruit and retain effective STEM teachers. Action in Teacher Education, 34, 541-550. http://dx.doi.org/10.1080/01626620.2012.729483

Izzo, M. V., Murray, A., \& Novak, J. (2008). The faculty perspective on Universal Design for Learning. Journal of Postsecondary Education and Disability, 21(2), 60-72.

Jackson S.L. (2009). Research methods and statistics: a critical thinking approach (3rd ed.). Belmont, CA: Wadsworth.

Jiménez, T. C., Graf, V. L., \& Rose, E. (2007). Gaining access to general education: the promise of Universal Design for Learning. Issues in Teacher Education, 16(2), 41-54.

Kennedy, B. H. (2013). A qualitative case study of the bilingual teacher shortage in one Texas school district (Doctoral dissertation). Available from ProQuest. (UMI No. 3606445)

Knapp, L., Kelly-Reid, J., \& Ginder, S. (2010). Enrollment in postsecondary institutions, fall 2008; graduation rates, 2002 \& 2005 cohorts; and financial statistics, fiscal year 2008 (NCES 2010152). Washington, DC: National Center for Education Statistics.

Lee, C. Y., Dickerson, J., \& Winslow, J. (2012). An analysis of organizational approaches to online course structures. Online Journal of Distance Learning Administration, 15(1).

Mangiatordi, A., \& Serenelli, F. (2013). Universal Design for Learning: a meta-analytic review of 80 abstracts from peer reviewed journals. REM, 5(1), 109-118.

Mcguire, J. M., Scott, S. S., \& Shaw, S. F. (2006). Universal design and its applications in educational environments. Remedial and special education, 27(3), 166-175.

Mebane, M., Porcelli, R., Iannone, A., Attanasio, C., \& Francescato, D. (2008). Evaluation of the efficacy of affective education online training in promoting academic and professional learning and social capital. International Journal of Human-Computer Interaction, 24(1), 68-86. 
Meo, G. (2008). Curriculum planning for all learners: applying Universal Design for Learning (UDL) to a high school reading comprehension program. Preventing School Failure: Alternative Education for Children and Youth, 52(2), 21-30.

Meyer, A, Rose, D. H. R., \& Gordon, D. (2014). Universal design for learning: theory and practice. Wakefield, MA: CAST Professional Publishing.

Morra, T., \& Reynolds, J. (2010). Universal Design for Learning: application for technology-enhanced learning. Inquiry, 15(1), 43-51.

National Center for Education Statistics. (2014). Web tables: enrollment in distance education courses, by state: Fall 2012. US Department of Education. [NCES 2014-023]. http://nces.ed.gov/pubs2014/2014023.pdf.

NCUDL (2013). How has UDL been defined? National Center On Universal Design for Learning website. Retrieved from http://www.udlcenter.org/aboutudl/udldefined

Pace, D., \& Schwartz, D. (2008). Accessibility in post secondary education: application of UDL to college curriculum. US-China Education Review, 5(12), 20-26.

Poore-Pariseau, C. (2010). Online learning: designing for all users. Journal of Usability studies, 5(4), 147-156.

Powell, R. G., \& Powell, D. (2010). Classroom communication and diversity: enhancing instructional practice. New York: Routledge.

Rao, K., \& Tanners, A. (2011). Curb cuts in cyberspace: Universal Instructional Design for online courses. Journal of Postsecondary Education and Disability, 24(3), 211-229.

Roberts, K. D., Park, H. J., Brown, S., \& Cook, B. (2011). Universal Design for Instruction in postsecondary education: a systematic review of empirically based articles. Journal of Postsecondary Education and Disability, 24(1), 5-15.

Rose, D. H., \& Meyer, A. (2002). Teaching every student in the digital age: Universal Design for Learning. Association for Supervision and Curriculum Development. Alexandria, VA: Association for Supervision \& Curriculum Development.

Rose, D., Meyer, A., \& Hitchcock, C. (2005). The universally designed classroom: accessible curriculum and digital technologies. Cambridge, MA: Harvard University Press

Scott, S., McGuire, J., \& Shaw, S. (2003). Universal design for instruction: a new paradigm for teaching adults in postsecondary education. Remedial and Special Education, 24(6), 369-379.

Smith, F. G. (2012). Analyzing a college course that adheres to the Universal Design for Learning (UDL) framework. Journal of the Scholarship of Teaching and Learning, 12(3), 31-61.

Smith, T.E.C., Polloway, E.A., Patton, J.R., \& Dowdy, C.A. (2001). Teaching students with special needs in inclusive settings, (3rd ed.). Boston: Allyn \& Bacon.

Spooner, F., Baker, J. N., Harris, A. A., Ahlgrim-Delzell, L., \& Browder, D. M. (2007). Effects of training in universal design for learning on lesson plan development. Remedial and Special Education, 28(2), 108-116. 
Tanner, J. R., Noser, T. C., \& Totaro, M. W. (2009). Business faculty and undergraduate students' perceptions of online learning: a comparative study. Journal of Information Systems Education, 20(1), 29.

Tayebinik, M., \& Puteh, M. (2013). Does greater participation in online courses lead to passing grade? An EFL learning context. British Journal of Educational Technology, 44(6), E199-E202.

Taylor, P., \& Maor, D. (2000). Assessing the efficacy of online teaching with the Constructivist Online Learning Environment Survey. In A. Herrmann and M.M. Kulski (Eds), Flexible Futures in Tertiary Teaching. Proceedings of the 9th Annual Teaching Learning Forum. Perth: Curtin University of Technology.

Thornton, B., Peltier, G., \& Medina, R. (2007). Reducing the special education teacher shortage. The Clearing House, 80(5), 233-238.

U.S. Department of Education, Office of Postsecondary Education. (2011). Preparing and credentialing the nation's teachers: the Secretary's eighth report on teacher quality; based on data provided for 2008, 2009 and 2010, Washington, D.C.

Vernon-Dotson, L. J., Floyd, L. O., Dukes, C., \& Darling, S. M. (2014). Course delivery: keystones of effective special education teacher preparation. Teacher Education and Special Education, 37, 34-50. doi: 10.1177/0888406413507728

Visser, P. S., Krosnick, J. A., \& Lavrakas, P. J. (2000). Survey research. In H. T. Reis \& C. M. Judd (Ed.), Handbook of research methods in social psychology (pp. 223-252). New York, NY: Cambridge University Press.

Xu, D., \& Jaggars, S. S. (2011). The effectiveness of distance education across Virginia's community colleges: evidence from introductory college-level math and English courses. Educational Evaluation and Policy Analysis, 33(3), 360-377. 


\section{Appendix A: Online Course and UDL Survey}

Which of the following best describes your reason for taking the course?

- $C$ Degree Requirement

- $\mathrm{C}$ Elective Course

- $C$ Professional Development

- O Other

What gender do you identify with?

- 5 Male

- $\mathrm{F}$ Female

What is your age?

- $C<20$ Years

- 20-30 Years

- $30-40$ Years

- $40-50$ Years

- $50+$ Years

I accessed the course website with the following tools:

- $\Gamma$ Computer (Desktop, laptop, Mac or PC)

- $\square$ Mobile Phone

- $\Gamma$ Tablet

- $\Gamma$ Internet-enabled Television

- $\Gamma$ Other:

What is your race/ethnicity?

- $r$ African-American

- $C$ Asian/Pacific Islander

- $\mathrm{H}$ Hispanic/Latino

- $C$ Caucasian/White

- $C$ Other:

Have you taken an online course before?

- $\mathrm{C}$ Yes

- $\mathrm{No}$ 
How experienced are you with online courses?

- $\mathrm{C}$ Very experienced

- $\mathrm{C}$ Somewhat experienced

- $\mathrm{C}$ Casually experienced

- $\mathrm{C}$ Somewhat inexperienced

- $\mathrm{V}$ Very inexperienced

Rate your agreement with the following phrase: The learning objectives for this course were clear.

- Completely agree

- $\mathrm{C}$ Somewhat agree

- $\quad$ Neither agree nor disagree

- $\mathrm{S}$ Somewhat disagree

- $\mathrm{C}$ Completely disagree

Rate your agreement with the following phrase: The course website was easy to use.

- Completely agree

- $\mathrm{S}$ Somewhat agree

- $C$ Neither agree nor disagree

- $\mathrm{S}$ Somewhat disagree

- $C$ Completely disagree

Rate your agreement with the following phrase: The course website is a good platform to showcase my learning.

- $\quad$ Completely agree

- $\mathrm{C}$ Somewhat agree

- $\mathrm{C}$ Neither agree nor disagree

- $\mathrm{S}$ Somewhat disagree

- $\mathrm{C}$ Completely disagree

How easily were you able to find information on the website? It was easy to find the information I needed on the course website?

- $C$ Completely agree

- $C$ Somewhat agree

- $C$ Neither agree nor disagree

- $C$ Somewhat disagree

- $\mathrm{C}$ Completely disagree 
- $\quad$ Rate your agreement with the following phrase: I was able to interact with peers using the course website.

- $C$ Completely agree

- $r$ Somewhat agree

- $\mathrm{C}$ Neither agree nor disagree

- $\mathrm{S}$ Somewhat disagree

- Completely disagree

Rate your agreement with the following phrase: I was able to interact with my instructor using the course website.

- $C$ Completely agree

- $\mathrm{C}$ Somewhat agree

- $C$ Neither agree nor disagree

- $C$ Somewhat disagree

- $\mathrm{C}$ Completely disagree

Rate your agreement with the following phrase: The layout of the course website was well-organized.

- Completely agree

- $\mathrm{C}$ Somewhat agree

- $C$ Neither agree nor disagree

- $C$ Somewhat disagree

- $\mathrm{C}$ Completely disagree

Rate your agreement with the following phrase: Resources used were helpful in completing this course.

- $C$ Completely agree

- Somewhat agree

- $C$ Neither agree nor disagree

- $\mathrm{S}$ Somewhat disagree

- $C$ Completely disagree

Rate your agreement with the following phrase: I would take another course using this course website design.

- $C$ Completely agree

- $\mathrm{C}$ Somewhat agree

- $C$ Neither agree nor disagree

- $\mathrm{S}$ Somewhat disagree

- $\mathrm{C}$ Completely disagree 
Rate your agreement with the following phrase: This course provided content in multiple, adjustable formats (text, video, audio, etc).

- $\mathrm{C}$ Completely Agree

- $\mathrm{C}$ Agree

- $\mathrm{O}$ Neither agree nor disagree

- $\mathrm{C}$ Disagree

- $C$ Completely Disagree

Rate your agreement with the following phrase: Information in this course was presented to me in multiple ways (video, audio, text, etc).

- $C$ Completely Agree

- $C$ Agree

- $C$ Neither agree nor disagree

- $C$ Disagree

- $\mathrm{C}$ Completely Disagree

Rate your agreement with the following phrase: Assignments or activities in this course were provided in multiple formats.

- $C$ Completely Agree

- $\bigcirc$ Agree

- $C$ Neither agree nor disagree

- $\mathrm{D}$ Disagree

- $\mathrm{C}$ Absolutely Disagree

Rate your agreement with the following phrase: My learning/preparation was positively impacted as a result of the content being presented in multiple ways.

- $\mathrm{C}$ Completely Agree

- $O$ Agree

- $C$ Neither agree nor disagree

- $\mathrm{C}$ Disagree

- $C$ Absolutely Disagree 
Rate your agreement with the following phrase: The course offered multiple ways to complete tasks.

- Absolutely Agree

- $C$ Agree

- $\quad$ Neither agree nor disagree

- $\mathrm{C}$ Disagree

- $C$ Absolutely Disagree

Rate your agreement with the following phrase: This course allowed for multiple ways to express or communicate my knowledge.

- Absolutely Agree

- $C$ Agree

- $\quad$ Neither agree nor disagree

- $\mathrm{C}$ Disagree

- $\mathrm{C}$ Absolutely Disagree

Rate your agreement with the following phrase: The course encouraged the use of technology to express my knowledge.

- Absolutely Agree

- $C$ Agree

- $C$ Neither agree nor disagree

- $\mathrm{D}$ Disagree

- $C$ Absolutely Disagree

Rate your agreement with the following phrase: My learning/preparation was positively impacted as a result of having multiple ways to express or communicate my knowledge.

- $\mathrm{C}$ Absolutely Agree

- $C$ Agree

- $C$ Neither agree nor disagree

- $\mathrm{D}$ Disagree

- $\mathrm{C}$ Absolutely Disagree

Rate your agreement with the following phrase: The course material was relevant and had value.

- $\mathrm{C}$ Completely agree

- $C$ Agree

- $C$ Neither agree nor disagree

- $\mathrm{C}$ Disagree

- $C$ Completely Disagree 
Rate your agreement with the following phrase: This course was a motivation to learn more about the subject matter.

- $C$ Completely Agree

- $\bigcirc$ Agree

- $\mathrm{C}$ Neither agree nor disagree

- $C$ Disagree

- $C$ Completely Disagree

Rate your agreement with the following phrase: This course website offered opportunities to become engaged in learning.

- $C$ Completely Agree

- $C$ Agree

- $\quad$ Neither agree nor disagree

- $\mathrm{D}$ Disagree

- $C$ Completely Disagree

Rate your agreement with the following phrase: This course offered multiple instructional methods that allowed me to become involved in the learning process.

- $C$ Completely Agree

- $\bigcirc$ Agree

- $C$ Neither agree nor disagree

- $\mathrm{C}$ Disagree

- $\mathrm{C}$ Completely Disagree

Rate your agreement with the following phrase: My learning/preparation was positively impacted as a result of becoming engaged in the learning process.

- $C$ Completely Agree

- $C$ Agree

- $\quad$ Neither agree nor disagree

- $\mathrm{D}$ Disagree

- $C$ Completely Disagree 